\title{
PEMBUATAN DAN KARAKTERISASI KATALIS ZEOLIT ZSM-5 UNTUK KONVERSI BIOETANOL MENJADI BIOETILENA
}

\section{SYNTHESIS AND CHARACTERISATION OF ZSM-5 ZEOLITE CATAL YST FOR BIOETHANOL TO BIOETHYLENE CONVERSION}

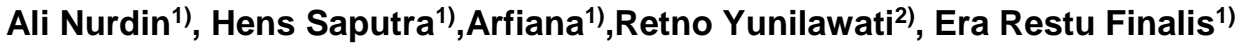 \\ ${ }^{1}$ Pusat Teknologi Sumberdaya Energi dan Industri Kimia - TIEM \\ Badan Pengkajian dan Penerapan Teknologi \\ Gedung 225 PUSPIPTEK Tangerang Selatan \\ ali.nur@bppt.go.id \\ Balai Besar Kimia dan Kemasan \\ Kementerian Perindustrian Rl \\ Jl.Balai Kimia No.1 Pekayon, Pasar Rebo Jakarta Timur \\ eno_nila@yahoo.com
}

\begin{abstract}
Abstrak
Etilena sebagai produk petrokimia yang penting dapat dibuat dari bioetanol menggunakan katalis ZSM-5. Katalis zeolit sintetis dengan struktur ZSM-5 cukup mahal dan belum dapat diproduksi di dalam negeri. Zeolit sintetis ZSM-5 dapat dibuat menggunakan zeolit alam yang banyak tersedia di Indonesia. Proses pembuatan ZSM-5 menggunakan metode hidrotermal pada temperatur $180^{\circ} \mathrm{C}$ selama 24 jam. Sebagai agen pengarah terbentuknya struktur ZSM-5 tersebut digunakan template TPABr (Tetra Prophyl Ammonium Bromide). Kalsinasi produk ZSM-5 dilakukan pada temperatur $600^{\circ} \mathrm{C}$ selama 1 jam. Karakterisasi ZSM-5 yang dilakukan antara lain analisis struktur dan kristalinitas, observasi morfologi permukaan menggunakan metode Difraksi Sinar X, Scanning Electron Microscopy, dan physisorption untuk mempelajari sifat pori. Hasil penelitian menunjukkan bahwa dihasilkannya ZSM-5 dengan kristalinitas sekitar 110 $\%$. Kristal ZSM-5 yang dihasilkan berbentuk kubus dengan luas permukaan spesifik BET $300 \mathrm{~m}^{2} / \mathrm{g}$, volume pori sekitar $0,13 \mathrm{~cm} / \mathrm{g}$. Distribusi ukuran pori yang sempit mengindikasikan ukuran pori yang seragam dengan ukuran rata-rata $0,55 \mathrm{~nm}$. Hasil uji coba katalis ZSM-5 pada produksi etilena menunjukkan bahwa selektivitas etilena meningkat seiring dengan kenaikan suhu reaksi.
\end{abstract}

Kata kunci : katalis, zeolit, ZSM-5, bioetanol, bioetilena.

\begin{abstract}
Ethylene as the important petrochemical product could be produced from bioethanol using ZSM-5 catalyst. The synthetic zeolite catalysts with ZSM5 structure are expensive and cannot be produced domestically. The synthetic ZSM-5 zeolite could be prepared using natural zeolite which are abundant available in Indonesia. The synthesize process of ZSM-5 was occurred by hydrothermal method at $180^{\circ} \mathrm{C}$ for 24 hours. Organic template agent of ZSM-5 structure was used TPABr (Tetra Prophyl Ammonium Bromide). Calcination of the obtained ZSM- 5 was conducted at $600^{\circ} \mathrm{C}$ for 1 hour. The characterization of synthesized ZSM- 5 such as structure and crystallinity analysis using X-ray diffraction (XRD), surface morphology observation using Scanning Elecgtron Microscope and physisorption for
\end{abstract}


study of pore characteristic. The results show ZSM-5 structure with crystallinity ca. $110 \%$. The obtained ZSM- 5 crystal was cubic with BET specific surface area ca. $300 \mathrm{~m}^{2} / \mathrm{g}$, pore volume $0.13 \mathrm{~cm}^{3} . \mathrm{g}$. The narrow pore size distribution was indicating homogen pore size, average $0.55 \mathrm{~nm}$. The production bioethylena by using zeolite ZSM-5 shows that the selectivity of ethylene increases with the increase of reaction temperature.

Keywords: catalyst, zeolite, ZSM-5, bioethanol, bioethylene

Diterima (received ) : 7 Juni 2018, Direvisi (revised ) : 16 Agustus 2018

Disetujui (accepted) : 20 Agustus 2018

\section{PENDAHULUAN}

Etilena merupakan salah satu produk petrokimia yang berperan penting pada sintesis produk petrokimia lainnya. Hampir $75 \%$ produk petrokimia merupakan turunan dari etilena ${ }^{1)}$ diantaranya asetaldehida, asam asetat, etilen oksida, etilen glikol, dan sebagainya. Selain itu etilena juga digunakan sebagai monomer pada pembuatan plastik seperti polietilena, polivinil klorida, dan polistirena ${ }^{1}$. Etilena di Indonesia diproduksi oleh PT. Chandra Asri Petrochemical yang menggunakan bahan baku nafta. Nafta tersebut diimpor dari Timur Tengah dengan biaya yang mahal. Dengan semakin terbatasnya cadangan minyak bumi maka perlu dicari alternatif bahan baku untuk membuat etilena tersebut. Bioetanol $\left(\mathrm{C}_{2} \mathrm{H}_{5} \mathrm{OH}\right)$ yang merupakan bahan terbarukan dapat dijadikan alternatif bahan baku untuk membuat bioetilena $\left(\mathrm{C}_{2} \mathrm{H}_{4}\right)$ dengan metode reaksi dehidrasi menggunakan katalis ${ }^{2-4)}$.

Reaksi dehidrasi etanol menjadi etilena pada umumnya berlangsung pada temperatur $180{ }^{\circ} \mathrm{C}-500{ }^{\circ} \mathrm{C}$. Katalis yang digunakan antara lain silicoaluminophosphates (SAPO), $\quad \mathrm{\gamma Al}_{2} \mathrm{O}_{3}$, heteropolyacids, dan zeolit ZSM-5 3-5). Katalis ZSM-5 memiliki selektivitas yang tinggi dan konversi yang besar serta dapat bekerja dalam temperatur yang tidak terlalu tinggi pada reaksi dehidrasi etanol sehingga penggunaan katalis HZSM-5 ini sangat menjanjikan. Pada saat ini harga zeolit sintetis dengan struktur ZSM-5 cukup mahal dan belum dapat diproduksi di dalam negeri. Ketergantungan katalis impor dapat menjadi masalah bagi industri bioetilena.

Indonesia memiliki sumberdaya zeolit alam yang berlimpah dan pada saat ini diketahui tersebar di beberapa daerah pesisir di Sumatera, Jawa, Sulawesi dan Indonesia Timur6). Zeolit alam memiliki kelemahan dalam aplikasinya karena adanya bahan pengotor dan strukturnya yang tidak seragam, cenderung campuran dari beberapa struktur zeolit maupun non zeolit69). Pada penelitian ini dilakukan pembuatan katalis zeolit sintetis ZSM-5 untuk konversi bioetanol menjadi bioetilena dengan menggunakan bahan baku zeolit alam. Katalis yang dihasilkan dikarakterisasi ${ }^{10)}$ yang meliputi validasi struktur zeolit menggunakan $X$-ray diffraction, observasi struktur mikro, profil adsorpsi-desorpsi isothermal nitrogen pada temperatur $44 \mathrm{~K}$, distribusi ukuran pori, luas permukaan, ukuran pori serta volume porinya yang sangat relevan dengan fungsinya sebagai katalis. Selain itu juga dilakukan uji coba kinerja katalis pada konversi bioetanol menjadi bioetilena.

\section{METODA PENELITIAN}

\section{Bahan dan Alat}

Bahan yang digunakan terdiri dari zeolit alam asal Kalianda Lampung Selatan, $\mathrm{NaOH}$ yang berfungsi sebagai katalisator, template organik TPABr (tetra propil ammonium bromide), natrium silikat untuk menambah silika, pelarut akuades, dan bioetanol

Alat yang digunakan antara lain $X$ ray diffraction (XRD) untuk mengidentifikasi struktur yang dihasilkan, Scanning Electron Microscopy (SEM) untuk observasi struktur mikro, autoklaf untuk proses hidrotermal dalam pembuatan zeolit sintetis, tanur yang digunakan untuk proses kalsinasi, dan Gas Chromatography Mass Spectrometry (GCMS) untuk analisis produk koversi.

\section{Pembuatan zeolit ZSM-5}

Larutan induk ZSM-5 disiapkan dengan mencampurkan larutan zeolit alam, narium silikat dan TPABr. Larutan zeolit alam dibuat dengan melarutkan zeolit alam 
kedalam larutan $\mathrm{NaOH}$. Campuran larutan induk ZSM-5 diaduk dengan kecepatan 300 rpm selama 1 jam. Selanjutnya campuran larutan yang dihasilkan dimasukkan ke dalam autoklaf dan dipanaskan secara konstan pada temperatur $180^{\circ} \mathrm{C}$ dengan tekanan autogenous. Kristal zeolit yang dihasilkan dari proses hidrotermal tersebut selanjutnya dipisahkan dari larutannya menggunakan kertas saring dan dicuci dengan akuades, kemudian dikeringkan dalam oven pada temperatur $100^{\circ} \mathrm{C}$ dan dikalsinasi pada temperatur 600. Produk yang dihasilkan berupa serbuk berwarna putih.

\section{Analisis dan Karakterisasi katalis ZSM-5}

Identifikasi struktur dan kristanilitas katalis dianalisis menggunakan difraksi sinar $X$ (XRD). Pengamatan mikrostruktur dilakukan menggunakan Scanning Elektron Microscopy (SEM). Karakteristik pori yang meliputi luas permukaan spesifik BrunauerEmmett- Teller (BET), volume pori dan ukuran pori ditentukan menggunakan Autosorb-1 (Quantachrome, USA). Diamati pula karakteristik adsorpsi-desorpsi isothermal nitrogen pada $44 \mathrm{~K}$.

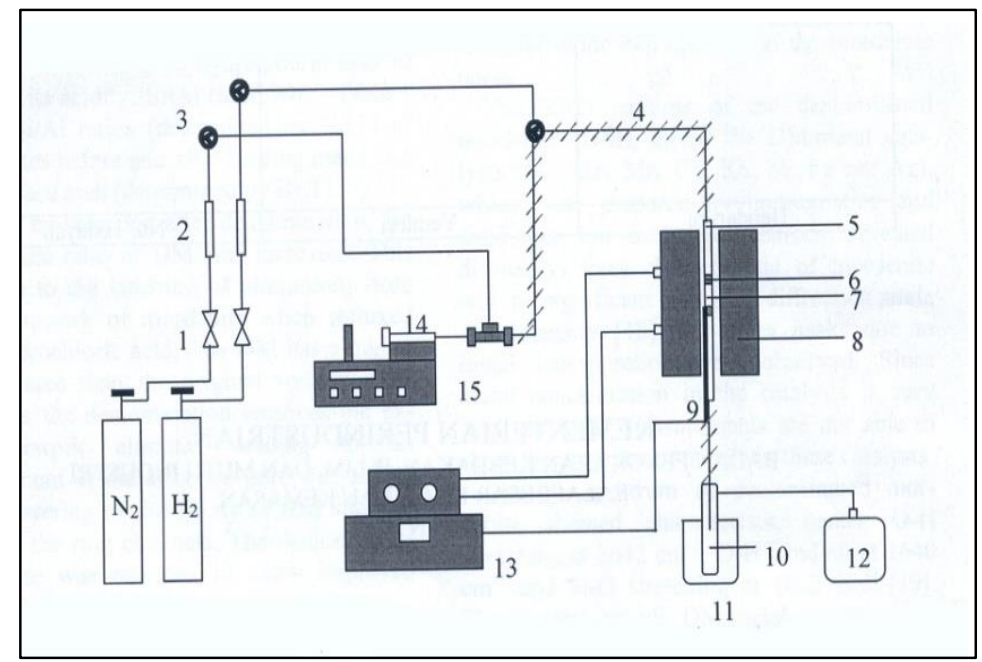

Gambar 1.

Skema reakor konversi bioetanol menjadi bioetilena

Keterangan :

1. Needle valve

2. Kontrol aliran gas

3. Katup 3 jalur

4. Kabel pemanas

5. Reaktor tubular

6. Quartz wool

7. Katalis

8. Furnace listrik
9. Termokopel

10. Cold trap

11. Dry ice-acetone bath

12. Tedlar bag

13. Pengontrol temperatur yang diprogram

14. Syringe

15. Syringe pump

\section{Uji coba kinerja katalis ZSM-5}

Katalis ZSM-5 yang dihasilkan selanjutnya diuji coba pada reaksi dehidrasi bioetanol menjadi bioetilena dengan dengan sistem instalasi reaktor percobaan seperti pada Gambar 1. Reaksi dehidrasi bioetanol untuk menghasilkan bioetilena ini dilakukan pada berbagai suhu antara $350^{\circ} \mathrm{C}-460^{\circ} \mathrm{C}$. Hasil reaksi yang berupa bioetilena diukur kadarnya menggunakan GCMS dan dihitung selektivitasnya.

\section{HASIL DAN PEMBAHASAN}

\section{Karakteristik katalis ZSM-5}

Katalis ZSM-5 yang dihasilkan berbentuk serbuk putih dengan karakteristik seperti yang ditunjukkan dalam Tabel 1 
Tabel 1.

Karakteristik katalis ZSM-5

\begin{tabular}{lll}
\hline \multicolumn{1}{c}{ Kriteria } & Nilai/keterangan \\
\hline Identifikasi menggunakan XRD & Pola difraksi sesuai & dengan \\
& standar ZSM-5 & \\
Pengamatan mikrostruktur menggunakan SEM & Berbentuk kubus \\
Luas permukaan metode BET & $300 \mathrm{~m}^{2} / \mathrm{g}$ \\
Volume pori & $0,13 \mathrm{~cm}^{3} / \mathrm{g}$ \\
Ukuran pori rata-rata & $0,55 \mathrm{~nm}$ \\
\hline
\end{tabular}

Identifikasi struktur zeolit sintetis ZSM-5 menggunakan XRD menghasilkan difraktogram ZSM-5 yang dapat dilihat pada Gambar 2. Berdasarkan Gambar 2 dapat diketahui adanya struktur ZSM5 pada serbuk katalis yang dihasilkan. Struktur ZSM5 ini dicirikan dengan sepuluh pola difraksi XRD sesuai dengan pola difraksi XRD ZSM-5 standar

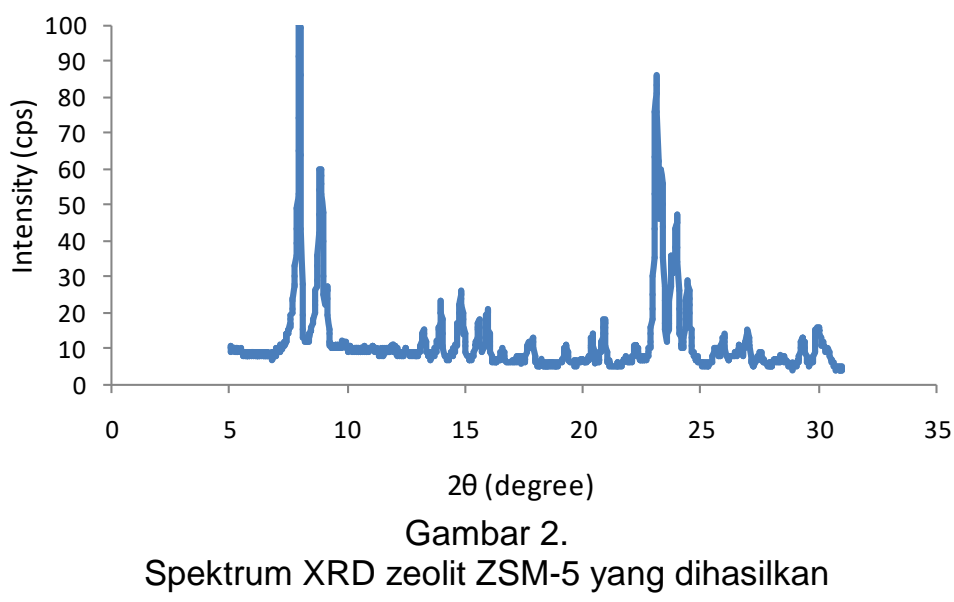

Pengamatan menggunakan SEM (Scanning Electron Microscopy) dilakukan untuk mempelajari struktur mikro. Berdasarkan hasil analisis SEM tersebut dapat dilihat adanya ketidakteraturan ukuran kristal zeolit, masih terdapat struktur berupa serabut dan gumpalan - gumpalan (Gambar 3). Adanya gumpalan tersebut mengindikasikan bahwa masih

terdapatnya kandungan air terikat pada kristal yang dihasilkan. Keseragaman dan keteraturan morfologi kristal akan memberikan aksesibilitas yang baik ke situs pusat aktif dan dapat memberikan mobilitas yang tinggi terhadap produk. Berdasarkan foto SEM tersebut dapat dilihat bahwa sampel yang dihasilkan berbentuk kubus yang merupakan ciri khas ZSM-5.

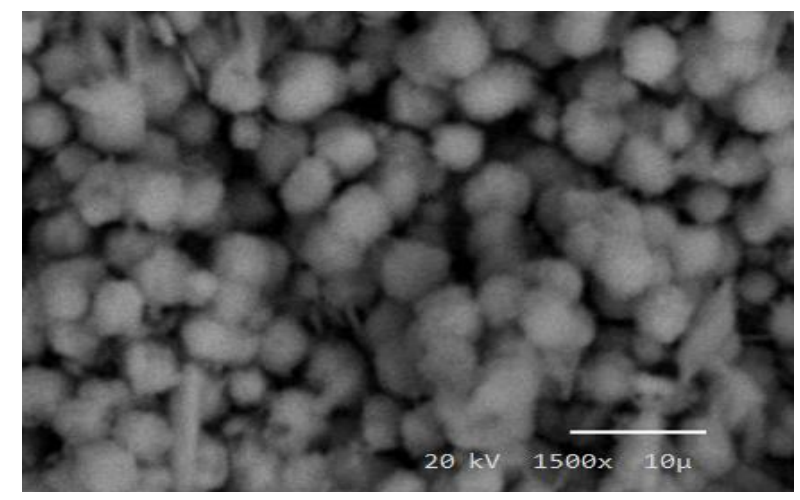

Gambar 3.

Foto SEM ZSM-5 yang dihasilkan 
Luas permukaan dan ukuran pori merupakan dua sifat mendasar yang sangat penting dalam karakteristik suatu katalis. Untuk menentukannya, dilakukan pengamatan physisorption ${ }^{11)}$.

Hasil analisis physisorption dapat dilihat pada Gambar 4. Adsorpsi-desorpsi isotermal dilakukan menggunakan nitrogen pada $44 \mathrm{~K}$. Pada daerah tekanan uap relatif kurang dari 0.1 terlihat adanya kenaikan kurva yang tinggi menunjukkan adanya pori berukuran mikro pada zeolit tersebut. Tidak tampak adanya pori berukuran makro. Namun terlihat adanya histeresis pada daerah mesopori. Histeresis tersebut kemungkinan mengindikasikan adanya perbedaan ukuran pori pada bagian permukaan dengan bagian dalamnya. Ukuran pori bagian dalam lebih besar dibandingkan dengan ukuran pori bagian luar, sehingga proses desorpsi menjadi lebih lambat dibandingkan dengan proses adsorpsi karena adanya gas nitrogen yang masih tersisa pada pori yang berbentuk seperti gua tersebut.

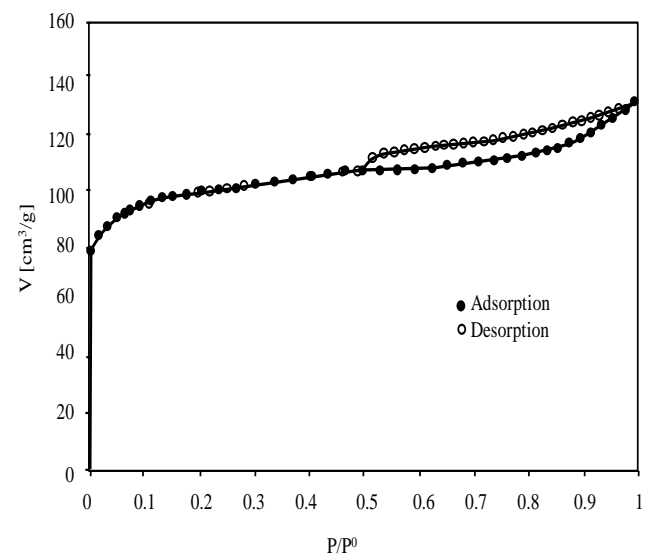

Gambar 4.

Adsorpsi-desorpsi isotermal nitrogen pada ZSM5

Luas permukaan spesifik pori, volume pori, dan ukuran pori dari produk yang dihasilkan dianalisis mengunakan metode BET (Brunauer, Emmett, Teller). Sifat-sifat pori seperti volume pori dan ukuran pori menjadi parameter penting terutama untuk katalis yang bersifat selektif terhadap bentuk dan ukuran pori. Menggunakan data physisorption seperti yang ditampilkan pada Gambar 3. Diperoleh luas permukaan sekitar $300 \mathrm{~m}^{2} / \mathrm{g}$ dengan volume pori sekitar $0.13 \mathrm{~cm}^{3} / \mathrm{g}$.Distribusi ukuran pori BJH (Barret Joyner Halenda) dapat dilihat pada Gambar 5.

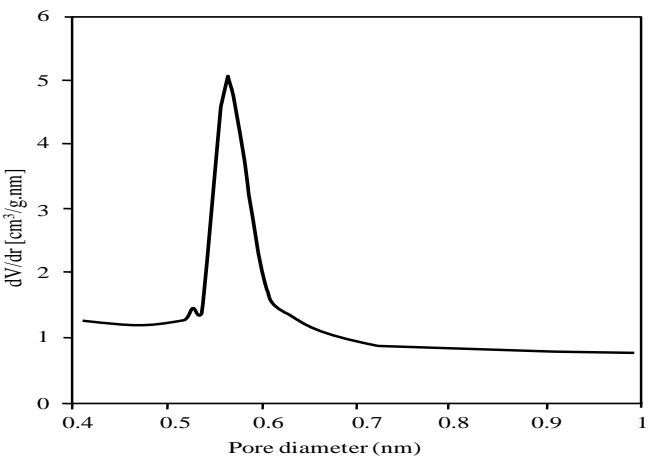

Gambar 5.

Distribusi ukuran pori ZSM5

Berdasarkan Gambar 4 dapat diketahui adanya distribusi ukuran pori yang sempit, menunjukkan ukuran pori yang homogen dengan ukuran rata-rata sekitar $0,55 \mathrm{~nm}$.

\section{Potensi Katalis HZSM-5 dalam Konversi Bioetanol menjadi Bioetilena}

Potensi katalis HZSM-5 dalam dehidrasi bioetanol menjadi bioetilen diperlihatkan dalam Gambar 6. Pada suhu reaksi $380^{\circ} \mathrm{C}$ selektivitas etilena baru mencapai sekitar $87 \%$. Selektivitas ini masih rendah karena reaksi yang berlangsung pada suhu rendah dapat menghasilkan produk dietil eter

Selektivitas etilena terus meningkat seiring dengan naiknya suhu reaksi. Selektivtas tertinggi dicapai pada suhu reaksi $460^{\circ} \mathrm{C}$ yang menghasilkan etilena dengan selektivitas sekitar $99 \%$.

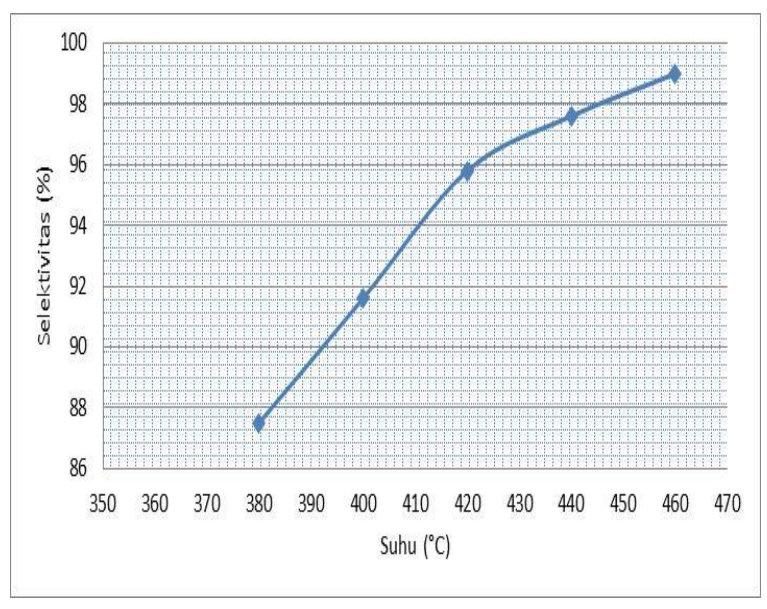

Gambar 6.

Grafik hubungan antara suhu dehidrasi bioetanol menggunakan katalis ZSM-5 dan selektivitas etilena yang dihasilkan 


\section{SIMPULAN}

Pada penelitian ini telah berhasil dibuat katalis ZSM-5 dari bahan baku zeolit yang berasal dari Lampung. Berdasarkan pengamatan menggunakan SEM, bentuk kristal ZSM-5 yang dihasilkan adalah kubik. Luas permukaan spesifik BET dan volume pori yang diperoleh adalah $300 \mathrm{~m}^{2} / \mathrm{g}$ dan $0,13 \mathrm{~cm}^{3} / \mathrm{g}$. Katalis ZSM-5 yang dihasilkan memiliki distribusi ukuran pori yang sempit dengan ukuran pori rata-rata sekitar $0,55 \mathrm{~nm}$. Katalis ZSM-5 yang dihasilkan dapat digunakan untuk konversi bioetanol menjadi bioetilena dengan selektivitas etilenaa yang meningkat seiring dengan kenaikan suhu reaksi. Selektivitas tertinggi dicapai pada suhu $480{ }^{\circ} \mathrm{C}$ dengan selektivitas etilena sekitar $99 \%$.

\section{UCAPAN TERIMAKASIH}

Penulis mengucapkan terima kasih kepada Kementerian Ristekdikti yang telah membiayai penelitian ini.

\section{DAFTAR PUSTAKA}

1. Rossetti, I., Matteo Compagnoni, ElisabettaFinocchio, GianguidoRamis, Alessandro Di Michele, YannickMillot, Stanislaw Dzwigaj, 2017, Ethylene production via catalytic dehydration of diluted bioethanol: A step towards an integrated biorefinery, Applied Catalysis B: Environmental 210 (2017) 407-420.

2. Chen, B., Jiazheng Lu, Lianping Wu, Zisheng Chao, 2016, Dehydration of bio-ethanol to ethylene over iron exchanged HZSM-5, Chinese Journal of Catalysis 37 (2016) 1941-1948.

3. Fan, D., Dai, D. J., \& Wu, H. S. 2012. Ethylene formation by catalytic dehydration of ethanol with industrial considerations. Materials, 6(1), 101115.

4. Wu, C. Y., \& Wu, H. S. 2017. Ethylene Formation from Ethanol Dehydration Using ZSM-5 Catalyst. ACS Omega, 2(8), 4287-4296.

5. Setiadi, S., Muhammad Nasikin. 2011. Catalytic Conversion of Acetone to Monoaromatic Chemicals Using HZSM5. University of Indonesia.

6. Kuiniasari, L. 2008, Potensi Zeolit Alam Sebagai Adsorben Air pada Alat Pengering, Jurnal IImiah Momentum ISSN 0216-7395, Universitas Wahid Hasyim, Semarang.

7. Widayat, A Sadikky DP, H Anggraeni, 2012, Proses Produksi Katalis Zeolit $X$ Dan Uji Aktifitas Dalam Proses Penukaran Ion Kalsium, TEKNIK - Vol. 33 No.1, 4-7.

8. Rochmat, A., Gheantika Merdeka, Vita Duwi Kumala Sari, 2016, Studi Pendahuluan Pemanfaatan Zeolit Alam Bayah Sebagai Katalis Pada Sintesis Gliserol Mono Oleat, Indonesia Natural Research Pharmaceutical Journal (Vol 1, No 1, 2016) Universitas 17 Agustus 1945 Jakarta

9. Fitrawansyah. 2012, Sintesis Gliserol Menjadi Gliserol Mono Oleat Dengan Katalisator Zeolit Alam Bayah, Tugas Akhir yang tidak dibukukan, Universitas Sultan Ageng Tirtayasa, Cilegon.

10. Anonim, 2017, Workshop Karakterisasi Zeolit, Lab. Energi, ITS, Surabaya.

11. Zhang, Z., Zhenghong Yang, 2013, Theoretical and practical discussion of measurement accuracy for physisorption with micro- and mesoporous materials, Chinese Journal of Catalysis 34 (2013) 1797-1810. 